\title{
Peningkatan HSV dan Haar-Like Feature pada Aplikasi Identifikasi Kematangan Buah Tomat Berbasis Android
}

\author{
Febri Liantoni $^{\mathrm{a} 1}$, Nurcahya Pradana Taufik Prakisya ${ }^{\mathrm{a} 2}$, Yusfia Hafid Aristyagama ${ }^{\mathrm{a} 3}$ \\ a Pendidikan Teknik Informatika dan Komputer, Universitas Sebelas Maret \\ 1febri.liantoni@gmail.com \\ ${ }^{2}$ nurcahya.pradana@gmail.com \\ ${ }^{3}$ yusfia.hafidz@gmail.com
}

\begin{abstract}
Abstrak
Tomat adalah buah yang terkenal karena memiliki banyak nutrisi penting dan bermanfaat seperti antioksidan, vitamin C dan A untuk makanan sehari-hari manusia. Memetik tomat dengan tangan merupakan pekerjaan yang berat dan memakan waktu. Karena itu, untuk mengatasi masalah ini, tomat perlu diambil secara otomatis dengan bantuan teknologi. Baru-baru ini otomatisasi panen buah memperoleh popularitas besar. Untuk memandu robot pemanen mengambil buah dengan benar, penting untuk mendeteksi dan menemukan lokasi buah matang merah dengan benar. Maka dibutuhkan aplikasi untuk identifikasi kematangan buah tomat. Dalam penelitian ini, algoritma pendeteksian tomat matang berdasarkan ruang warna HSV (Hue, Saturation, Value) yang ditingkatkan dengan haar-like feature. Metode ini diterapakan pada aplikasi berbasis android. Pada tahap pertama, transformasi HSV digunakan untuk menghilangkan latar belakang dan hanya mendeteksi tomat merah. Kemudian operasi morfologis diterapkan untuk memodifikasi buah yang terdeteksi. Hasil penelitian mampu mendeteksi tomat matang merah dengan peningkatan HSV dan haar-like feature.
\end{abstract}

Kata kunci: android, haar-like feature, HSV, tomat

\section{Title is Bold and Each Letter is Written Capital Except for Conjunctions}

\begin{abstract}
Tomato is a well-known fruit because of its nutrition such as antioxidant, vitamin $\mathrm{C}$, and vitamin A. Picking tomato manually is a hard and time-consuming activity. So that, to overcome this problem, the tomato should be harvested automatically with the help of technology. Recently, fruit harvest automation receives big popularity. To train harvesting robots choosing ripe tomatoes, it is important to detect and find the right location. So that, application to identify the ripeness of tomatoes is needed. In this study, an algorithm for detecting ripe tomatoes based on HSV (Hue, Saturation, Value) color space enhanced with haar-like features. This method is applied to the android based application. In the first stage, HSV transformation is used to remove the background and only detect red tomatoes. Then morphological operations are applied to modify the detected fruit. The results of the study can detect red ripe tomatoes with increased HSV and haar-like features.
\end{abstract}

Keywords: android, haar-like feature, HSV, tomato

\section{PEndahuluan}

Tomat dikenal sebagai salah satu buah paling populer di dunia. Buah tomat memiliki sumber yang kaya serat dan vitamin A dan C. Konsumsi tomat telah dikaitkan dengan penurunan risiko beberapa kanker, penyakit kardiovaskular, osteoporosis, dan sebagainya [1], [2]. Di seluruh dunia, tomat juga merupakan tanaman hortikultura yang penting, dan merupakan buah yang paling banyak diekspor [3], [4]. Mengetahui tingkat kematangan tomat penting untuk tujuan yang berbeda seperti prioritas transportasi ke pasar dan penyimpanan berdasarkan tahap kematangan tomat [5]. Secara tradisional, tomat diklasifikasikan berdasarkan kematangan fisiologisnya dengan penyortiran manual.
Namun, menyortir tomat dan buah-buahan lainnya adalah prosedur yang memakan waktu. Itu tergantung pada orang yang telah dilatih khusus dalam menyortir tomat. Keterampilan penyortir ini bervariasi dari orang ke orang oleh karena itu, penyortiran manual ini bukan proses yang akurat [6].

Warna adalah karakteristik kualitas buah yang sangat penting. Ini mewakili tingkat kedewasaan, kandungan gula, keasaman, dan rasa. Misalnya, di pasar buah segar seperti apel dan buah persik, warna merah gelap mewakili buah berkualitas lebih tinggi daripada merah terang. Fitur warna telah banyak diterapkan untuk evaluasi kualitas apel, sebagian besar untuk mendeteksi ketidaksempurnaan. 
Dalam hal ini, fitur warna setiap piksel dalam gambar yang diperoleh dari tiga komponen ruang merah, hijau, dan biru dapat secara efektif digunakan untuk membagi cacat dua varietas apel. Tomat adalah jenis produk yang fitur warnanya banyak digunakan sebagai indikator yang baik untuk mengenali tingkat kematangan [7].

Untuk meningkatkan kecepatan dan ketepatan penilaian tomat, penelitian telah dilakukan pada metode penilaian. Laykin pada tahun 2002 mengembangkan algoritma pemrosesan gambar untuk memberikan parameter kualitas seperti warna, homogenitas warna, cacat, bentuk, dan deteksi batang untuk klasifikasi tomat [8]. Percobaan menghasilkan 90\% klasifikasi memar yang benar dengan $2 \%$ kesalahan klasifikasi, 90\% klasifikasi homogenitas warna yang benar, 92\% deteksi warna yang benar dengan $2 \%$ kesalahan klasifikasi, dan $100 \%$ deteksi batang. Pada penelitian sebelumnya citra warna HSV digunakan dalam klasifikasi kematangan cabai menggunakan Fuzzy $K$ Nearest Neighbor [9].

Mayoritas penelitian sebelumnya tentang mendeteksi kematangan tomat telah dilakukan untuk aplikasi penyortiran. Pada penelitian ini dirancang aplikasi berbasis android utnuk menngidentifiaksi kematangan buah tomat.

\section{Metodologi Penelitian}

Penelitian selalu diawali dengan proses pengkajian yang berkaitan dengan topik penelitian yang diambil. Proses ini meliputi pencarian referensi pendukung yang sesuai dan dapat dipertanggungjawabakan. Referensi yang digunakan dapat berupa buku atau artikel. Seperti, mengenai metode haar-like feature yang bisa mendeteksi tomat, klasifikasi kematangan tomat, tingkatan RGB dan HSV. Informasi yang didapat nantinya berguna untuk membantu mendesain algoritma untuk memecahkan permasalahan yang sedang diteliti saat ini. Setelah studi literatur dilakukan, pendefinisian masalah dapat diketahui lebih detail dan lebih teliti lagi.

\section{A. Tomat}

Tomat memiliki ukuran yang bermacam - macam serta memiliki tingkat kematangan yang dilihat dari warna kulit [10], [11]. Contoh foto tomat dengan tingkat kematangan yang berbeda-beda seperti ditunjukkan pada Gambar 1 berikut ini.

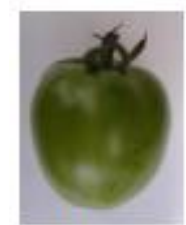

Level 1

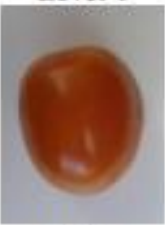

Level 4

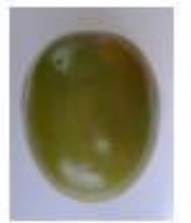

Level 2

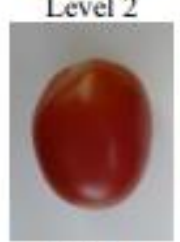

Level 5

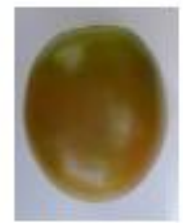

Level 3

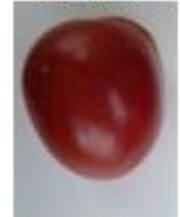

Level 6
Gambar 1. Level kematangan tomat

\section{B. HSV (Hue, Saturation, Value)}

Untuk mendapatkan nilai warna HSV, RGB yang didapatkan dari citra tomat yang telah dilakukan segmentasi akan di konversi kedalam ruang warna HSV [9], [12]. Nilai hue, saturation, value didapatkan setelah melakukan perhitungan menggunakan persamaan berikut.

$$
\begin{gathered}
\mathrm{C}_{\max }=\max \left(\mathrm{R}^{\prime} \mathrm{G}^{\prime} \mathrm{B}^{\prime}\right) \\
\mathrm{C}_{\min }=\min \left(\mathrm{R}^{\prime} \mathrm{G}^{\prime} \mathrm{B}^{\prime}\right) \\
\Delta=\mathrm{C}_{\max }-\mathrm{C}_{\min }
\end{gathered}
$$

$$
\begin{gathered}
\text { Hue Calculation: } \\
\left\{\begin{array}{c}
60^{0} \times\left(\frac{\mathrm{G}^{\prime}-\mathrm{B}^{\prime}}{\Delta} \bmod 6\right), \mathrm{C}_{\max }=\mathrm{R}^{\prime} \\
60^{0} \mathrm{x}\left(\frac{\mathrm{B}^{\prime}-\mathrm{R}^{\prime}}{\Delta}+2\right), \mathrm{C}_{\max }=\mathrm{G}^{\prime} \\
60^{0} \times\left(\frac{\mathrm{R}^{\prime}-\mathrm{G}^{\prime}}{\Delta}+4\right), \mathrm{C}_{\max }=\mathrm{B}^{\prime}
\end{array}\right.
\end{gathered}
$$

$$
\begin{aligned}
& \text { Saturation calculation: } \\
& \qquad S= \begin{cases}0, & \Delta=0 \\
\frac{\Delta}{\mathrm{C}_{\max }} & \Delta<>0\end{cases}
\end{aligned}
$$

Value calculation:

$$
\mathrm{V}=\mathrm{C}_{\max }
$$

Dimana $R$ adalah nilai warna merah, $G$ adalah nilai hijau, dan $B$ adalah nilai biru. $C_{\max }$ merupakan nilai konstanta terbesar diantara nilai $\mathrm{R}, \mathrm{G}, \mathrm{B}$, sedangkan $C_{\text {min }}$ merupakan nilai konstanta terkecil dari R,G, B. Hue merupakan suatu ukuran panjang gelombang yang terdapat pada warna dominan yang diterima oleh penglihatan. Saturation $(S)$ merupakan ukuran banyaknya cahaya putih yang bercampur pada hue. Value $(V)$ merupakan nilai kecerahan dari warna [12], [13]. Nilainya berkisar antara 0$100 \%$, apabila nilai 0 maka warnanya akan menjadi hitam, semakin besar nilai maka semakin cerah dan muncul variasi baru dari warna tersebut.

Tingkat Kematangan tomat dapat dilihat dari warna kulit tomat dengan tingkatan level dan range warna berdasarkan nilai HSV (Hue, Saturation, Value) [14]. Nilai tingkatan HSV seperti ditunjukkan pada Gambar 2 berikut. 


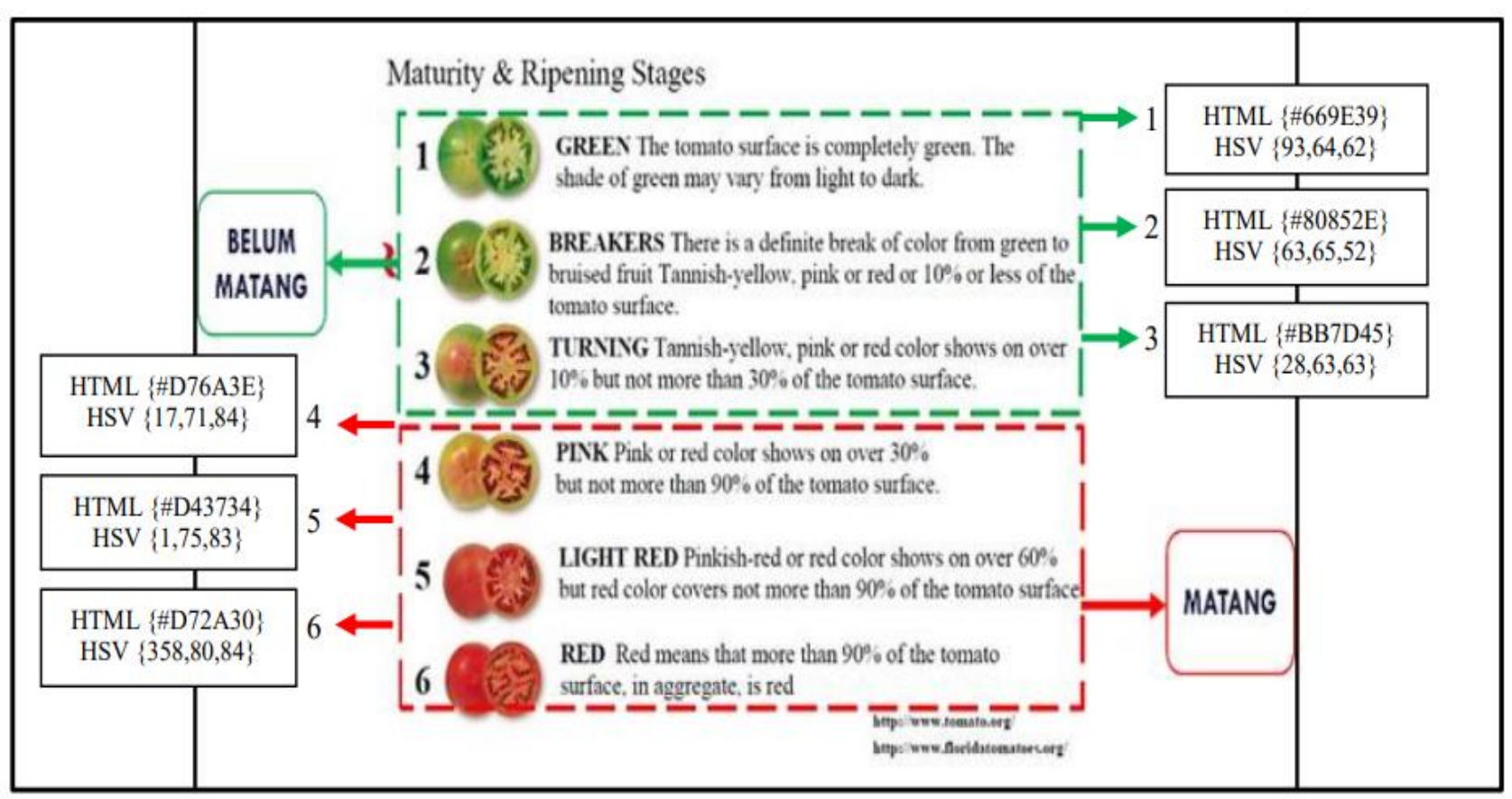

Gambar 2. Kematangan buah tomat

\section{Haar-Like feature}

Pada penelitian ini proses identifikasi dengan menerapkan metode segmentasi Haar-like feature dan segmentasi HSV menggunakan ambang gabungan. Proses Haar-like feature diperlukan untuk mendapatkan posisi buah tomat yang ada pada data citra. Deskriptor Haar-like didasarkan pada konsep gambar integral untuk mempercepat perhitungan fitur haar dan classifier multilayer tipe perceptron [15], [16]. Fitur Haar-like merupakan sekumpulan fungsi Haar dua dimensi (2D) yang lengkap, yang dapat digunakan untuk menampilkan dan mengolah tampilan objek lokal. Perancangan metode untuk identifikasi kematangan buah dengan menghitung segmentasi menggunakan Haar-like dengan proses menormalisasi HSV terlebih dahulu kemudian dilanjukan untuk perhitungan integral setalah mendapatkan fitur yang diinginkan lalu menghitung dengan menggunakan tingkatan HSV. Haar-like features bekerja dengan cara mengenali obyek berdasarkan nilai sederhana dari fitur tetapi bukan merupakan nilai piksel dari image obyek tersebut [16], [17]. Alur proses untuk mendapatkan ekstraksi warna merah dari citra tomat seperti ditunjukkan pada Gambar 3 berikut ini.

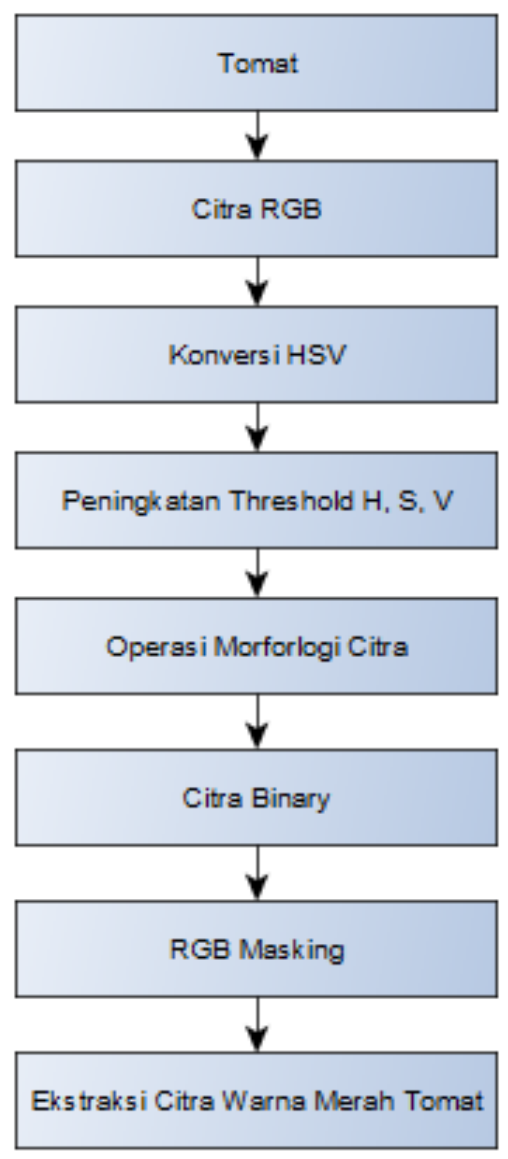

Gambar 3. Proses alur ekstraksi warna merah tomat

Sedangkan alur proses Haar-like seperti ditunjukkan pada Gambar 4. 


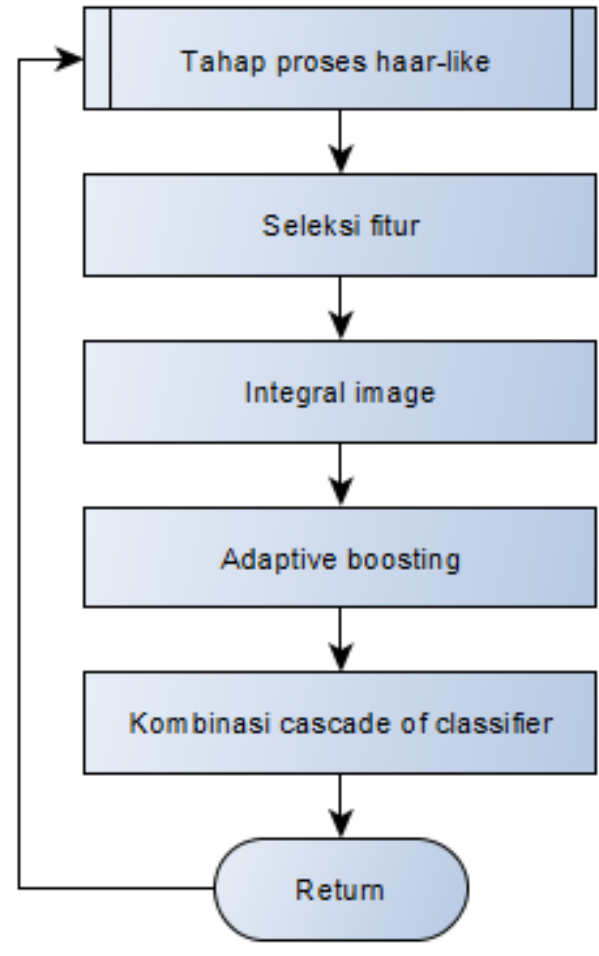

Gambar 4. Proses alur Haar-like

Pada Gambar 4 objek tomat akan dicari menggunakan Haar-like feature dimana citra yang ada akan diseleksi fitur dengan menggunakan perhitungan HSV dan di normalisasi sehingga mendapatkan hasil kemudian dilakukan proses perhitungan integral image dari hasil normalisai sebelumnya. Dengan Adaptive Boosting dan kombinasi Cascade of Classifier akan mempercepat pendeteksian objek tomat. Jika tomat terdeteksi, akan dilakukan penggambaran garis persegi pada tomat tersebut. Proses ini digunakan untuk mengidentifikasi buah tomat yang sudah matang. Proses identifikasi ini dengan menggunakan data training citra tomat matang yang digunakan sebagai pembanding dalam proses identifikasi.

\section{HASIL DAN PEMBAHASAN}

Pengujian dilakukan untuk mengindentifikasi buah tomat. Pengujian dengan membandingan buah tomat dengan objek lain untuk mengetahui keakuratan sistem android yang telah dibangun.

Contoh pengujian identifikasi buah tomat seperti ditunjukkan pada Gambar 5 dan Gambar 6. Pada Gambar 5 menunjukkan buah tomat matang dapat diidentifikasi dengan adanya kotak berwarna hijau. Cara pengambilan foto dilakukan dengan jarak dekat. Sedangkan pada Gambar 6 proses pengambilan foto dilakukan dengan jarak lebih jauh. Hasil identifikasi tomat matang menghasilkan garis kotak hijau secara bertingkat.

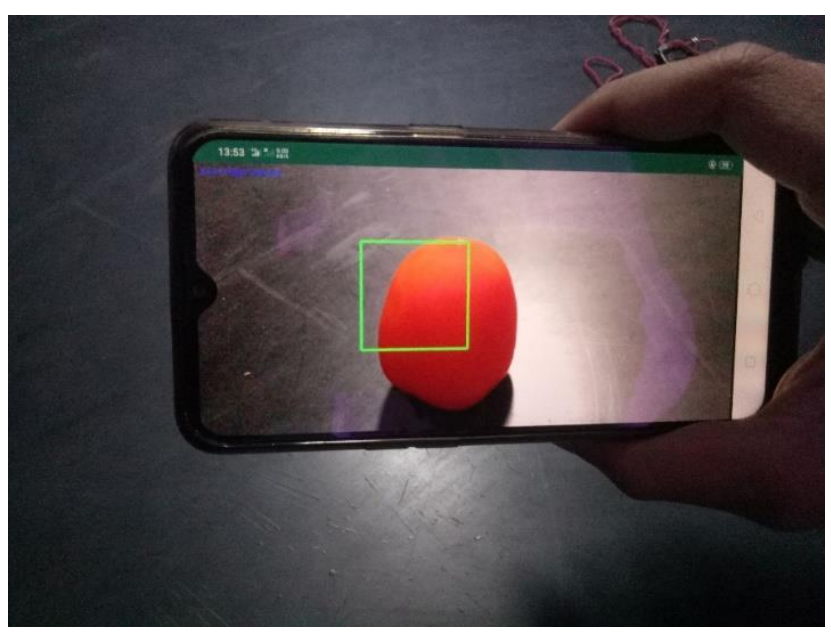

Gambar 5. Identifikasi buah tomat 1

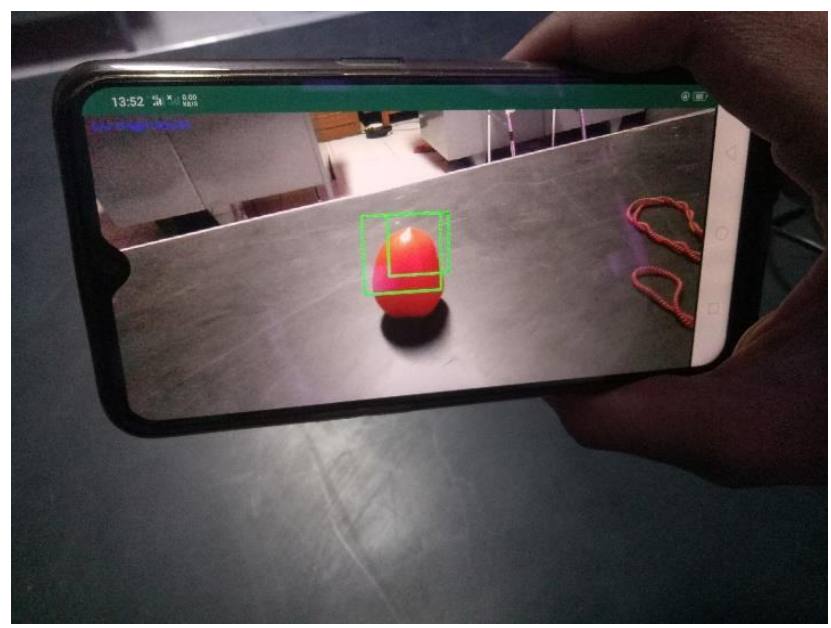

Gambar 6. Identifikasi buah tomat 2

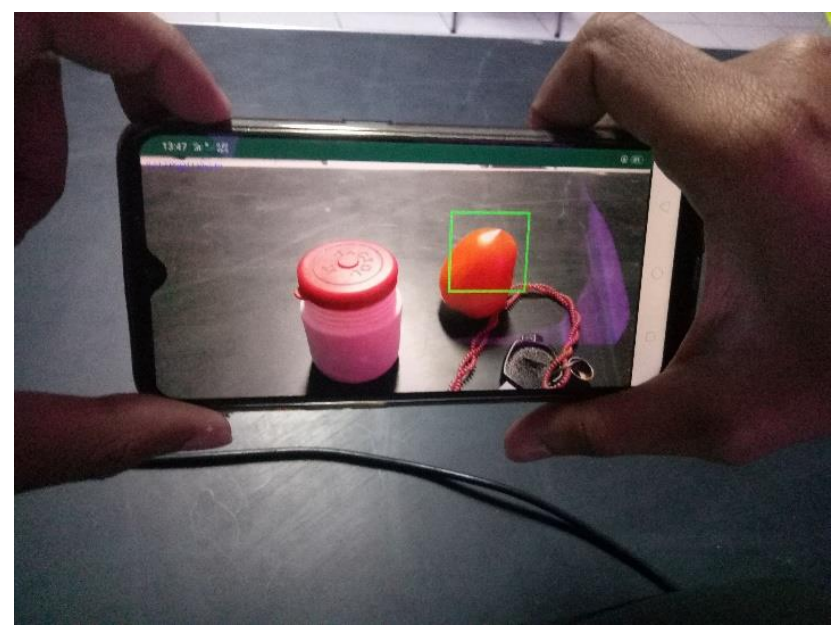

Gambar 7. Identifikasi buah tomat dengan 2 objek lain

Pada Gambar 7 pengujian dilakukan dengan objek yang memiliki warna merah. Hasil pengujian dengan 2 objek lain menunjukkan aplikasi android yang dibangun mampu mengidentifikasi tomat matang dengan baik. 
Pengujian juga dilakukan untuk objek yang lebih banyak untuk memastikan apakah apliaksi android yang dibangun tetap mampu mengidentifikasi tomat matang berdasarkan data training yang digunakan. Contoh pengujian dengan objek lebih banyak seperti ditunjukkan pada Gambar 8 berikut ini.

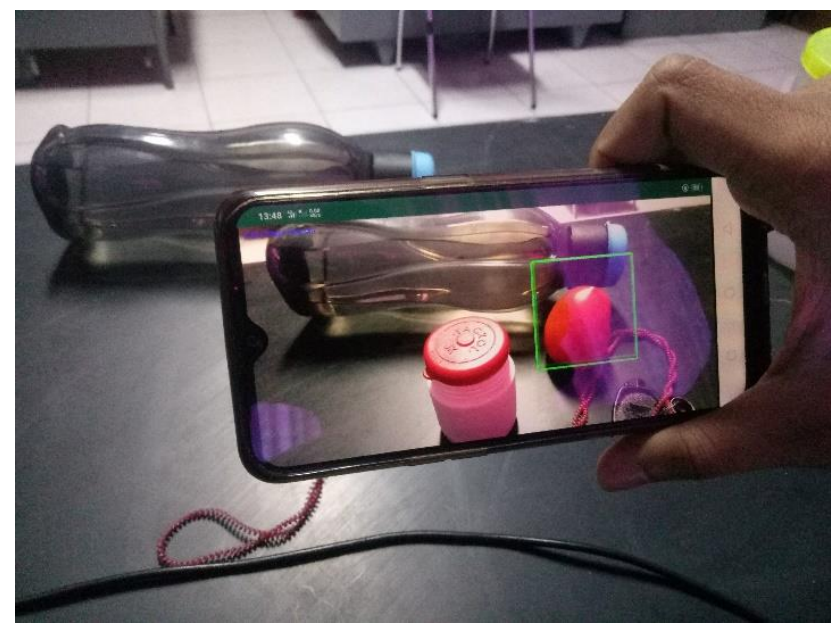

Gambar 8. Identifikasi buah tomat dengan 3 objek lain

Pada Gambar 7 pada proses identifikasi tomat dengan beberapa obejak lain menunjukkan aplikasi android yang dibangun mampu mengidentifikasi buah tomat matang dengan baik ditunjukkan dengan garis kotak hijau sebagai penanda buah tomat yang telah diidentifikasi.

\section{KESIMPULAN}

Pendekatan deteksi tomat matang mengggunakan gamabr berwarna telah dilakukan. Penggunaan bentuk, tekstur dan informasi warna, Haar-like feature dalam pengujian dan evaluasi. Penelitian ini dilakukan untuk mengeksplorasi kelayakan mendeteksi tomat matang hanya dengan menggunakan gambar berwarna biasa. Berdasarkan pengujian identifikasi kematangan buah tomah yang telah dilakukan menggunakan aplikasi android diperoleh kesimpulan bahwa sistem yang dibangun mampu mengidentifikasi buah tomat dengan baik dengan membandingkan dengan objek lain. Menurut algoritma yang diusulkan dan hasil diperoleh menggunakan warna gambar untuk deteksi tomat matang menunjukkan tingkat keberhasilan sudah baik.

\section{DAFTAR PUSTAKA}

[1] Saad, A.M., A. Ibrahim, and N. El-Bialee, "Internal quality assessment of tomato fruits using image color analysis," Agric. Eng. Int. CIGR J., vol. 18, pp. 339-352, 2016.

[2] Bhowmik, D., K. P. S. Kumar, S. Paswan, and S. Srivastava, "Tomato-a natural medicine and its health benefits," $J$ Pharmacogn. Phytochem, vol. 1, pp. 33-43, 2012.

[3] Y. Wei, M. Xu, H. Wu, S. Tu, L. Pan, and K. Tu, "Defense response of cherry tomato at different maturity stages to combined treatmen of hot air and Cryptococcus laurentii," Postharvest Biol. Technol., vol. 117, pp. 177-186, Jul. 2016, doi: 10.1016/j.postharvbio.2016.03.001.

[4] B. Van de Poel et al., "Model-based classification of tomato fruit development and ripening related to physiological maturity," Postharvest Biol. Technol., vol. 67, pp. 59-67, May 2012, doi: 10.1016/j.postharvbio.2011.12.005.

[5] Q. Xiao, W. Niu, and H. Zhang, "Predicting fruit maturity stage dynamically based on fuzzy recognition and color feature," in 6th IEEE International Conference on Software Engineering and Service Science (ICSESS), 2015, pp. 944-948.

[6] M. R. Satpute and S. M. Jagdale, "Color, size, volume, shape and texture feature extraction techniques for fruits: a review," Int. Res. J. Eng. Technol., vol. 3, pp. 703-708, 2016.

[7] S. Arivazhagan, S. S. Shebiah, R.N., Nidhyanandhan, and L. Ganesan, "Fruit recognition using color and texture features," $J$. Emerg. Trends Comput. Inform. Sci, vol. 1, pp. 90-94, 2010.

[8] S. Laykin, V. Alchanatis, E. Fallik, and Y. Edan, "Image Processing Algorithms For Tomato Classification," Trans. ASAE, vol. 45, no. 3, 2002, doi: 10.13031/2013.8838.

[9] F. Liantoni and F. N. Annisa, "Fuzzy K-Nearest Neighbor Pada Klasifikasi Kematangan Cabai Berdasarkan Fitur HSV Citra,” JIPI (Jurnal Ilm. Penelit. dan Pembelajaran Inform., vol. 3, no. 2, Dec. 2018, doi: 10.29100/jipi.v3i2.851.

[10] A. F. Smith, The Tomato in America: Early History, Culture and Cookery. University of Illinois Press, 2001.

[11] S. Yulia Riska and P. Subekti, "Klasifikasi Level Kematangan Buah Tomat Berdasarkan Fitur Warna Menggunakan Multi-SVM," Dec. 2016. doi: 10.5281/JIMI.V1I1.8.

[12] V. Chernov, J. Alander, and V. Bochko, "Integer-based accurate conversion between RGB and HSV color spaces," Comput. Electr. Eng., vol. 46, pp. 328-337, 2015, doi: 10.1016/j.compeleceng.2015.08.005.

[13] Z.-H. Li, D. Han, C.-J. Yang, T.-Y. Zhang, and H.-Q. Yu, "Probing operational conditions of mixing and oxygen deficiency using HSV color space," J. Environ. Manage, vol. 232, pp. 985-992, Feb. 2019, doi: 10.1016/j.jenvman.2018.12.025.

[14] K. B. Shaik, P. Ganesan, V. Kalist, B. S. Sathish, and J. M. M. Jenitha, "Comparative Study of Skin Color Detection and Segmentation in HSV and YCbCr Color Space," Procedia Comput. Sci., vol. 57, pp. 41-48, 2015, doi: 10.1016/j.procs.2015.07.362.

[15] S.-K. Pavani, D. Delgado, and A. F. Frangi, "Haar-like features with optimally weighted rectangles for rapid object detection," Pattern Recognit., vol. 43, no. 1, pp. 160-172, Jan. 2010, doi: 10.1016/j.patcog.2009.05.011.

[16] B. Mohamed, A. Issam, A. Mohamed, and B. Abdellatif, "ECG Image Classification in Real time based on the Haar-like Features and Artificial Neural Networks," Procedia Comput. Sci., vol. 73, pp. 32-39, 2015, doi: 10.1016/j.procs.2015.12.045.

[17] A. Mohamed, A. Issam, B. Mohamed, and B. Abdellatif, "Realtime Detection of Vehicles Using the Haar-like Features and Artificial Neuron Networks," Procedia Comput. Sci., vol. 73, pp. 24-31, 2015, doi: 10.1016/j.procs.2015.12.044. 